\title{
CONCEPT OF TUBULAR DESIGN IN HIGH RISE STRUCTURES
}

[Vikram J \& Geethu Varghese]

\begin{abstract}
Multi-storeyed buildings are used for office, complex, residential flats, public centres, etc. There is need for multi-storeyed building due to overcrowding of cities. These multistoreyed buildings can be transformed into tall buildings in order to achieve more floor space but occupy less land space. In the design of tall buildings, lateral loads play predominant role. The lateral loads are wind load and seismic load. There are various lateral load resisting systems such as braced frame system, moment resisting frame system, frame truss-interacting system, shear wall system, core and outrigger system and tubular system. The tubular system comprises various types such as framed tube, trussed tube, tube in tube and bundled tube. In this project, a plan has been created for the bundled tube comprising four tubes using Auto-cad.
\end{abstract}

Prof. Vikram Jothijayakumar

(Corresponding Author)

METS School of Engg, MALA, KERALA, INDIA

Prof.Geethu Varghese

Assistant Professor - Civil Engineering

METS School of Engg, MALA, KERALA, INDIA
The various loads such as dead load, live load and wind load are assigned using software. Analysis of the structure has been done using software. The components of the structure such as the slab, beam and column has been designed by manual calculations. The slab is designed as continuous slab. The load calculations for slab and beam are done manually. The load for column design has been obtained from staad analysis report. The pile foundation for the bundled tube structure has been designed. The two main components of pile foundation are pile and pile cap. The design of pile and pile cap has been done by manual calculations. The pile has been designed as a square pile. The design detailing of all the designs such as beam, column, slab, pile and pile cap has been made in Auto-cad.

Key words: Tall buildings; Lateral Loads; Tubular system; Bundled Tube. 


\section{INTRODUCTION}

A multi-storey building is a building that has multiple floors above ground.

Multi-storey buildings aim to increase the floor area of the building without increasing the area of the land. The multi-storey building can be transformed to tall building to increase the floor space further more. A building whose height creates different conditions in the design, construction, and use than those that exist in common buildings of a certain region and period. The tall building design is influenced by the lateral loads such as wind, seismic,etc.

\section{a. Lateral Load Resisting Systems}

Braced frames are cantilevered vertical trusses resisting lateral loads primarily through the axial stiffness of the frame members. The moment resisting frame consists of horizontal and vertical members rigidly connected together in a planar grid form which resists lateral loads primarily through the flexural stiffness of the members. Vertical trusses alone may provide resistance for buildings of up to about 20 stories depending on the height to width ratio of the system. Shear trusses, when combined with moment resisting frames, produce a frame-truss interacting system.

Shear walls are a type of structural system that provides lateral resistance to a building or structure. They resist "in-plane" loads that are applied along its height. The applied load is generally transferred to the wall by a diaphragm or collector or drag member. They are built in wood, concrete and masonry.

The outrigger systems may be formed in any combination of steel, concrete, or composite construction. These outriggers serve to reduce the overturning moment in the core that would otherwise act as a pure cantilever, and to transfer the reduced moment to columns outside the core by way of a tensioncompression couple, which takes advantage of the increased moment arm between these columns. This system reduces the associated potential core uplift forces.

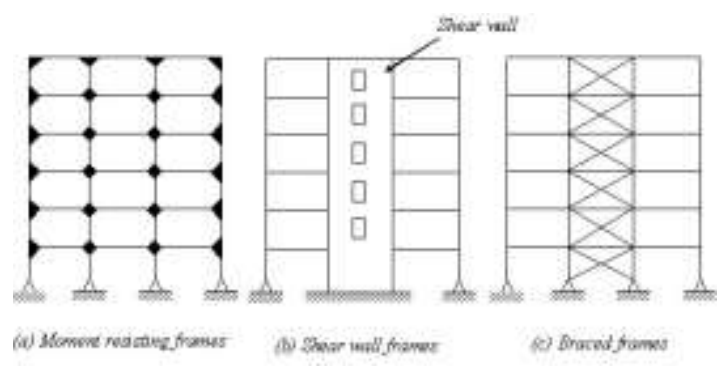

Figure 1. Types of Frames

\section{b. Tubular Systems}

The tube is the name given to the systems where in order to resist lateral loads (wind, seismic, etc.) a building is designed to act like a three-dimensional hollow tube, cantilevered perpendicular to the ground. The system was introduced by Fazlur Rahman Khan. Tubeframe construction was first used in the DeWitt-Chestnut Apartment Building, designed by Khan and completed in Chicago in 1963. 
The system can be constructed using steel, concrete, or composite construction (the discrete use of both steel and concrete). It can be used for office, apartment and mixed-use buildings.

Most buildings in excess of 40 stories constructed since the 1960 s are of this structural type.

\section{TYPES OF TUBE STRUCTURE}

\section{a. Framed Tube}

The organization of the framed tube system is generally one of the closely spaced exterior columns and deep spandrel beams rigidly connected together, with the entire assemblage continuous along each façade and around the building corners. The system is a logical extension of moment resisting frame whereby the beam and column stiffness are increased dramatically by reducing the clear span dimensions and increasing the member depths.

\section{b. Trussed Tube}

In trussed tube structure, the exterior face combines vertical, horizontal and diagonal members all of which are rigidly connected. The diagonal members carry gravity loads as well as lateral loads. The external tube resists entire shear as well as bending and the interior structure carries only gravitational loads. It is also known as the braced tube, it is similar to the simple tube but with comparatively fewer and farther-spaced exterior columns.

\section{Tube-In-Tube Structures}

This is a type of framed tube consisting of an outer-framed tube together with an internal elevator and service core. The exterior tube and the interior tube are designed to act together. The exterior tube has relatively large width and hence it is designed to resist the entire bending moment caused by lateral forces. The interior tubes are designed to carry shear produced by the lateral forces. This type of structures is also called as Hull (Outer tube) and Core (Inner tube) structures.

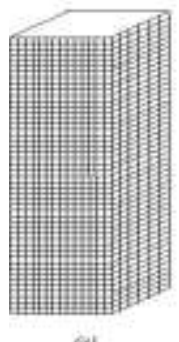

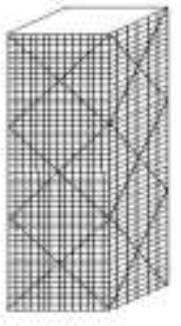

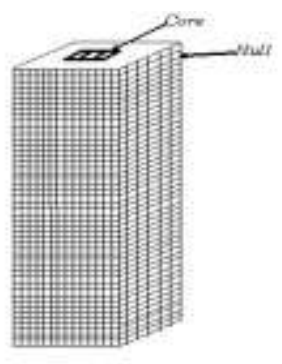

(a)framed tube(b)trussed tube(c)tube in tube

Figure 2. Types of tube structure

\section{c. Bundled Tube}

The bundled tube system can be visualised as an assemblage of individual tubes resulting in multiple cell tube to resist the lateral loads. The increase in stiffness is apparent. The system allows for the greatest 
height and the most floor area. This structural form was used in the Sears Tower in Chicago.The bundle tube design was not only highly efficient in economic terms, but it was also "innovative in its potential for versatile formulation of architectural space.

\section{PLAN AND ELEVATION}

A plan has been created for the bundled tube structure comprising of four tubes having a plinth area of $63.6 \mathrm{~m}$ by $63.6 \mathrm{~m}$. The elevation of the structure consists of $\mathrm{G}+70$ storeys with storey height as $3.5 \mathrm{~m}$.



Figure 3. Plan of bundled tube using CADD

\section{DESIGN CONCEPT}

The frame tube concept is the rigid connection of closely spaced exterior columns and deep spandrel beams. This system is a logical extension of moment resisting frame. The three dimensional structural system utilizes the entire building inertia to resist lateral loads. The tube system concept is based on the idea that a building can be designed to resist lateral loads by designing it as a hollow cantilever perpendicular to the ground.

This exterior framing is designed sufficiently strong to resist all lateral loads on the building, thereby allowing the interior of the building to be simply framed for gravity loads. Interior columns are comparatively few and located at the core. The distance between the exterior and the core frames is spanned with beams or trusses and intentionally left column-free. This maximizes the effectiveness of the perimeter tube by transferring some of the gravity loads within the structure to it and increases its ability to resist overturning due to lateral loads. Horizontal loads (primarily wind) are supported by the structure as a whole.

\section{STAAD-PRO APPLICATION}

The staad-pro software is applied for our project. Using staad-pro the modeling of the bundled tube structure is done for seventy storeys. The member property and support condition are assigned. The self weight of the structure is assigned. The live load is assigned for all the floors. The wind load is calculated for Coimbatore zone. The analysis of the entire structure is done. The results obtained are used for design. 


\section{WIRE FRAME MODEL}

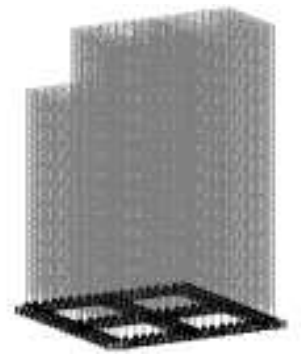

Figure 4. Shear diagram of a floor

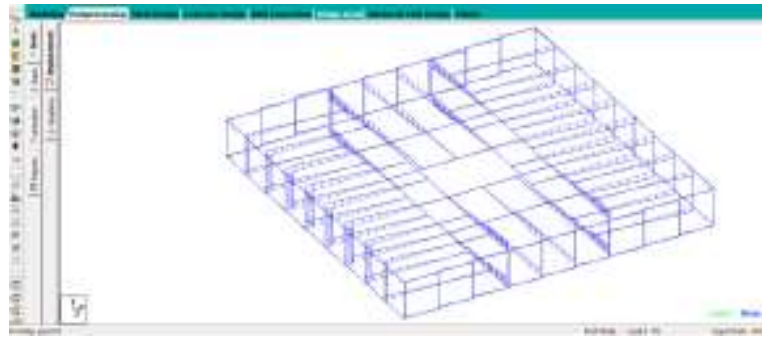

Figure 5. Bending moment diagram of a floor

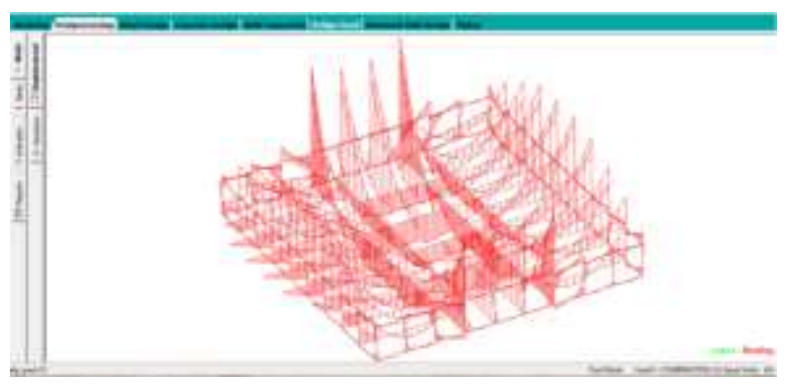

Figure 6. Beam stress diagram of a floor

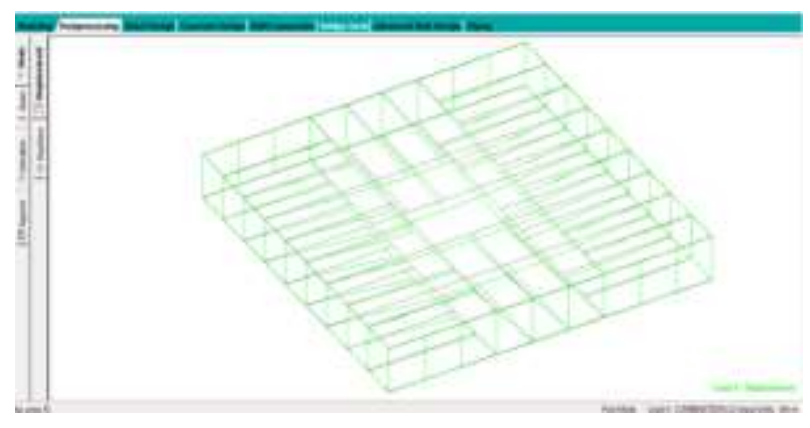

\section{CONCLUSION}

A plan for the bundled tube is created using Auto-cad. The modeling of the bundled tube structure is done using staad pro. The loads are assigned and analysis of the frame is done. The elements such as slab, beam and column are designed manually. The design of pile and pile cap is done by manual calculations. Not only tube structure, any tall building or multi-storeyed building is a better option for reduction of land use. In tube structure and other skyscrapers the curtain walls are used. This reduces the cladding cost. This kind of building construction improves the infrastructure of the country.

\section{References}

[1] J. J. Connor, Introduction to Structural Motion Control, New York: Prentice Hall, 2003.

[2] M. M. Ali and K. Moon, "Structural developments in tall buildings: Currents trends and future prospects," Architectural Science Review, vol. 50, no. 3, pp. 205-223, 2007.

[3]K.Moon, "Stiffness-based design methodology for steel braced tube structures: A sustainable approach," Engineering Structures, vol. 32, pp. 3163-3170, 2010.

[4] K. Moon, J. J. Connor, and J. E. Fernandez, "Diagrid structural systems for tall buildings: characteristics and methodology for preliminary design," The Structural Design of Tall and Special Buildings, vol. 16, no. 2, pp. 205-230, 2007.

[5]B. Smith and A. Coull, Tall Building Structures: Analysis and Design,New York: Wiley, 1991.

[6]E. Simiu and R. H. Scanlan, Wind Effects on Structures: Fundamentals and Applications to Design, 3rd Edition, New York: Wiley, 1996.

Figure 7. Displacement diagram of a floor 